\title{
Effective channels of communication of Ukrainian publishing houses with readers
}

\author{
T. Yezhyzhanska \\ Borys Grinchenko Kyiv University, Kyiv, Ukraine \\ Corresponding author. E-mail: t.yezhyzhanska@kubg.edu.ua
}

Paper received 06.05.21; Accepted for publication 20.05.21.

\section{https://doi.org/10.31174/SEND-HS2021-254IX46-18}

\begin{abstract}
The article presents the results of a survey devoted to identifying problems of communication of book publishing houses of Ukraine with readers and buyers of their products. Priority communication channels have been identified, from which readers will learn about publishers' news and book market events.

Keywords: book publishing houses, promotion, marketing, PR, book market.
\end{abstract}

Introduction. Ukraine's publishing industry is currently in crisis. One of the causes of the crisis was the COVID-19 pandemic, the introduction of quarantine and blocking, which led to changes in people's media behavior [3], the closure of bookstores, libraries, the cancellation of presentations, exhibitions, fairs. In such a difficult situation, publishers try to organize various promotions and PR campaigns to influence the popularity of their publications. To identify sources of information about new books and events in the book market, communication channels that affect the sale of books, we conducted a survey, the results of which are presented in this article.

Sociological surveys related to reading and book publishing in Ukraine are conducted mainly by state institutions, in particular the Ukrainian Book Institute. The allUkrainian big project "Ukrainian Reading and Publishing Data 2018" from the cultural and publishing project Chytomo, analytical Razumkov Centre and a digital publishing house Gutenbergz, the results of which are presented on the website Ukrainian Reading and Publishing Data 2018 http://data.chytomo.com [5].

The main questions of this poll concern the state of the modern publishing market and readers' preferences of Ukrainians. Some questions (for example, reasons for book selection) intersect with the questions in our study, so it would be appropriate to compare the answers, given that the survey was conducted at the same time. In 2020, the governmental organization Ukrainian Book Institute commissioned an all-Ukrainian sociological survey "Reading in the context of media consumption and life design" [4]. This study is important because its organizers aimed to study the typology of readers in the context of media consumption and identify effective channels of communication with them. Questions from this study (about leisure and frequency of reading magazines, watching television, listening to the radio) help to understand the behavior of readers and buyers of books. In addition to these questions, it is important to find out how often readers and shoppers use the Internet, in which social networks they spend the most time. The difference between our research and the above is that our research is aimed directly at identifying priority sources of information about new books and book market events. The study is relevant because publishers, like any organization, have great opportunities to promote their products, but often do not know how to use them to inform their potential readers or buyers and influence sales. This poll was conducted to answer this question.

Analysis of recent researches and publications. The state of Ukrainian book market at the present stage, in particular its communication challenges, is studied by both Ukrainian and foreign scientists, in particular digital transformations in the publishing industry - M. Zhenchenko, communication innovations - S. Vodolazka, publishing marketing V. Teremko. Interesting from the point of view of advertising and promotion of publications are the works of T. Bulakh, I. Kopystynska, A. Sudyn, which covers theoretical and practical issues of advertising and marketing in publishing, emphasizes the importance of promoting publications among the main tools of book marketing. N. Zelinska, O. Skiban, and O. Skochynets have partially researched the promotion of book editions in traditional and modern Ukrainian media. H. Klyuchkovska's dissertation is devoted to book promotion in the media, but more than 20 years have passed since the study, during which time significant changes have taken place in the development of the media space, and new opportunities and information channels have appeared in publishing houses [2]. The role of mass media and social media in the formation of the culture of reading Ukrainian books in the information society in the dissertation was clarified by A. Bessarab [1].

Thus, many works of Ukrainian scholars are devoted to the topic of popularizing reading, promoting books in traditional and modern Ukrainian media, but they did not study the opinions of readers and buyers of books on sources of information about the book publishing market. It is worth looking at the problem more broadly, analyzing the various channels from which readers receive information and which publishers can use to inform readers about books, as the topic requires a comprehensive approach.

The purpose of the study. The purpose of the article is to identify sources for obtaining information about the activities of the publishing house, to find out the prospects of the publishing house's use of mass media and the Internet to promote book editions.

Materials and methods. Our survey was conducted in the fall of 2019. The survey involved 200 respondents people who visited the Book Forum Lviv, the largest Ukrainian book fair and one of the most popular events of its kind in Eastern Europe. The survey was conducted using a questionnaire, respondents had to fill out a paper version of the questionnaires. The sample consisted of people who voluntarily answered the questionnaire. Additional questions about the age, gender, income level, place of residence and employment of the respondents allowed to study in more detail the answers of specific groups of 
people. The purpose of the study was to find out where readers get information about new books and the activities of Ukrainian book publishing houses; determine which Internet sources are trusted; to investigate what information about the book market attracts the attention of respondents and what events organized by publishers' people attend.

Results of research. One of the key questions is where visitors to the book fair get information about new books and the activities of Ukrainian publishing houses. The purpose of the question is to identify the main information channels that people use to learn about new books. The results of the answers are presented in detail in figure 1 . To the question "Where do you get information about new books and activities of Ukrainian publishers: print media (newspapers, magazines), radio, television, Internet, bookstores, acquaintances, friends, colleagues, advertising, etc." it was necessary to choose sources of information about publishing houses and number them according to the level of priority, evaluate on a 7-point scale, where 1 is the main - the most important source, 7 - the least important.

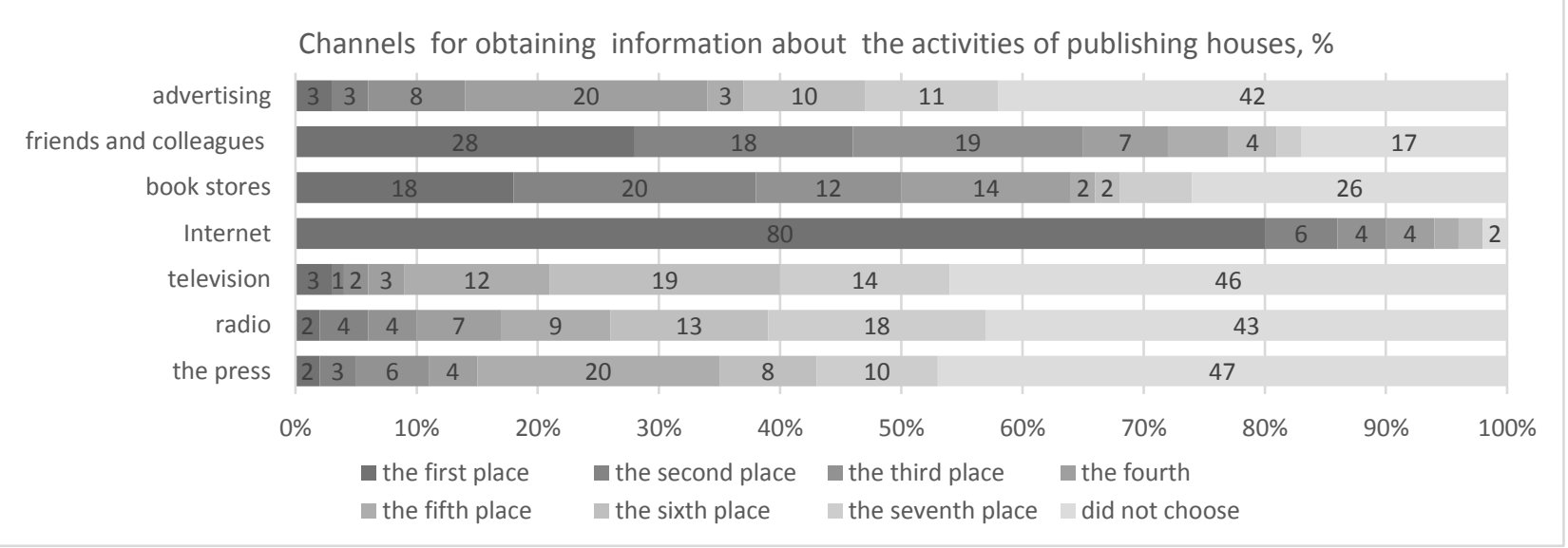

Figure 1. Channels for obtaining information about the activities of publishing houses.

Thus, the main source of information is the Internet, only $2 \%$ of respondents do not use it to obtain information, and $80 \%$ of respondents put it in the first place. Interestingly, in second place in the importance of informing about new books and activities of Ukrainian publishing houses not the media, but acquaintances, friends, colleagues (for $83 \%$, in addition, $28 \%$ of them put this source in the first place), and in third place - bookstores (74\%, and $18 \%$ in the first place), where readers can directly get acquainted with new books. By the way, respondents do not rely too much on the advice or advice of sellers, rely on their own tastes, preferences, reading experience. The press is a source of information for $53 \%$ of respondents (47\% did not choose such a channel of information), but the largest number of respondents put this source in 5th place, as well as television. Interestingly, half of the $54 \%$ of respondents do not receive information from television (although in many answers - regret that there are no/few programs on TV dedicated to books and reading). Radio is a source of information for $57 \%$ of respondents, although almost all respondents put this source in the last place, and $43 \%$ did not choose such a channel of information.

Thus, according to the study, the priority source of information is the Internet (the choice of $98 \%$ of respondents), the lowest priority is an advertising and traditional media. Respondents' choice of the new media as information channels, in contrast to the traditional ones, is incorrectly explained by the age of the respondents, firstly, among the interviewed people of different ages, and secondly, mainly by middle-aged respondents $-30-50$ years. The problem is that information about new books and the activities of Ukrainian publishers is difficult to find in traditional and online media, and the Internet remains the only source of information where information about new books and publishing activities appears.

Since the Internet is identified by most respondents as the highest priority source of information, it was interesting to investigate from which Internet sources respondents draw information about events in the publishing industry, which Internet sources enjoy the most trust of readers. Respondents were asked to number the following channels by priority level (from 1 - most important to 7 - least important): websites of publishing house, official pages of publishing house in social networks, personal pages/blogs of publishers or authors, pages of profile communities in social networks, book internet shops, specialized Internet sites that write about literature and publishing, online media and more. The results of the answers are presented in detail in figure 2 .

According to the survey, respondents $(74 \%)$ receive information from the official pages of the publishing houses in social networks; from websites of publishing houses $72 \%$; personal pages/blogs of publishers or authors $-67 \%$, online bookstores $(50 \%)$, specialized websites (such as "Chytomo","Bukvoid","Litakcent"), which write about literature, publishing (49\%), a significant proportion of readers turn for information to profile communities (such as "My book") in social networks (48\%), online media, which on their pages cover issues of the promotion books or events in rubric "Culture" (such as https://www.pravda.com.ua , https://lb.ua, https://www.the-village.com.ua/ etc.) $-47 \%$.

However, it cannot be stated unequivocally that all online resources are used by many consumers of information at the same time. Yes, half of the respondents do not use the online bookstores, specialized websites, which write about literature, publishing, a profile communities in social networks and online media; one third of respondents do not use the websites or official pages of the publishing houses in social networks and personal pages/blogs of publishers, authors. 
Internet channels of information about the publishing industry, \%

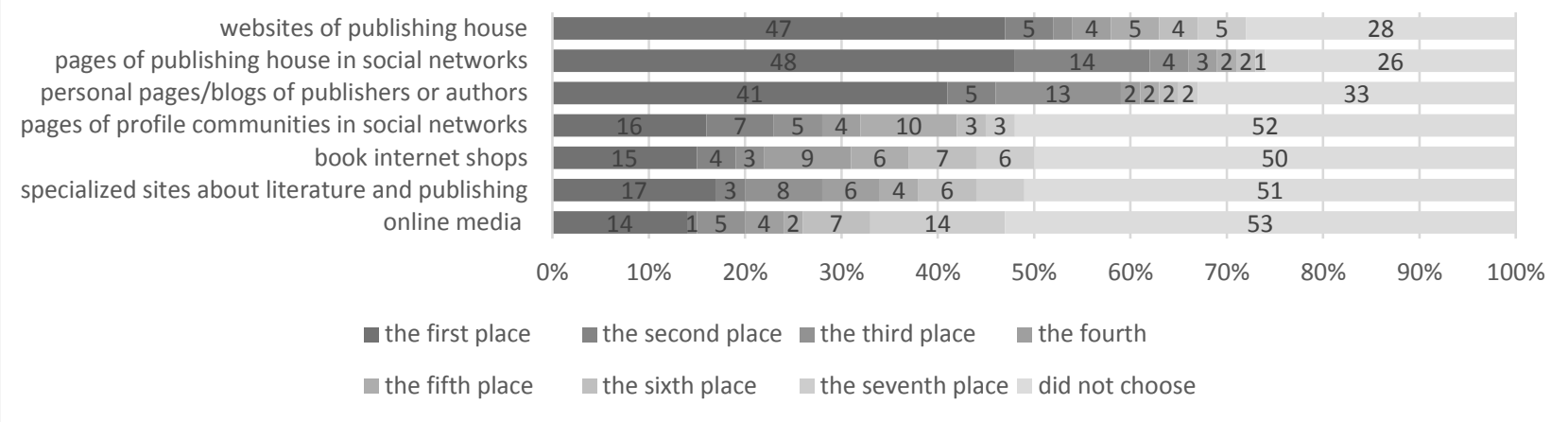

Figure 2. Internet channels of information about the publishing industry.

From the suggested answers of the respondents, we see that most respondents learn about new books from social networks and friends, get information on websites - more than a third, $53 \%$ - from newspapers and magazines, $54 \%$ - on television, $57 \%$ - on radio stations and $58 \%$ from advertising. It should be noted that the level of priority of media channels is quite low: only $2 \%$ of respondents put in the first place the press and radio and only $3 \%$ of respondents put television and advertising in the first place as the channel of information about the publishing industry.

As can be seen from the results of the study, the Internet, in particular social networks, is a significant source of information, because the results of surveys show that many respondents learn about new books on social networks. Interestingly, people's recommendations are also one of the priority channels for obtaining information about new books and a motivating factor in choosing a book. A more detailed study of the role of readers in the communication of book publishing in Ukraine is presented in the publication "Book PR: do readers influence on the communication of publishing company?" [6]. Information channels, which are in front of the eyes of a large part of the audience (TV, advertising), are rarely used by publishers. TV channels have almost no programs dedicated to books or reading, and publishers do not have enough money for advertising, so people who are actively interested in modern literature and often buy books do not receive enough information from them because these channels do not broadcast it.

The answers of the respondents shows that they pay attention to news about books and the activities of publishing houses from different information channels depending on age, location, income level, field of employment. People who read a lot and buy books (namely such visitors to the book fair Book Forum Lviv) learn about book news through various information channels (television, radio and advertising). This shows that this audience pays attention to news from the book world.

It was equally important to find out the information needs of readers about the book market. To the question of the questionnaire "What information about the book market attracts your attention?" respondents had to choose several options: about new books, about authors, about presentations, competitions, exhibitions, about the cost of books, and more. The dynamics of the structure of information needs about the book market is such that the greatest interest in new books (the vast majority $(62 \%)$ identified such information as a priority, and all are interested in such messages $-68 \%$ ), two thirds of respondents $(60 \%)$ are primarily interested in various events in the book market presentations, competitions, exhibitions, and more than half $(56 \%)$ prefer information about authors, and they are least interested in information about the cost of books (92\% of respondents - do not pay attention to such information). Some respondents acknowledged that price is important. This is evidenced by the answer to the question about the factors of choice of the book by readers, where the price was mentioned as an important factor for $86 \%$ of respondents, although they did not put it in the first place, but only in the third, fourth, fifth places.

It can be argued that the information needs of readers are high and diverse, they are interested in new books, authors, events in the publishing industry (presentations, competitions, exhibitions), without putting information about the price of the book in the first place. Among other things, respondents said that they were interested in "current topics, about publishing houses", "about publishing news", "only information about books of a certain genre", "I do not follow the news, I learn information from friends and acquaintances" and so on. The answer to the question about the information requests of the visitors of the book forum will help the PR managers of the book publishing houses to decide on the topics of PR-messages, to choose the appropriate communication tools.

It was important for us to find out whether the respondents attended events organized by publishers. According to the survey, most respondents $(76 \%)$ say they attend book presentations, autograph sessions of writers, almost half (52\%) say they attend specialized book exhibitions and forums, only $12 \%$ follow the awards, the announcement of the winners of the competition, $8 \%$ of respondents answered that they do not attend any events held in the book publishing industry. Let me remind you that the research was conducted at the International Book Forum Lviv - the most important and most anticipated book, literary and cultural event of the year in Ukraine. The purpose of the Book Forum is to draw public attention to the most pressing issues of modern Ukrainian book publishing, to support the tradition of professional discussions and seminars. For its visitors, the forum itself is an important source of information about new books. Respondents also named bookstores and universities, colleges, or other educational institutions as places to attend, as well as individual publishers and local writers who initiate meetings with readers. During the pre-quarantine period, the country regularly 
hosted book exhibitions and festivals, publishers organized presentations in shops and clubs, meetings with authors and autograph sessions, various cultural events to promote their authors and their books. It is worth noting that people who have higher education and live in big cities - Kyiv, Lviv, where the biggest and most important events of the book publishing market of Ukraine - Book Arsenal and Book Forum - are most active in attending book cultural events.

It is interesting to compare the answers of our study with the results of a poll conducted by "Ukrainian Reading and Publishing Data 2018" from the cultural and publishing project Chytomo. The question "What most influences the choice of the book?" $46.2 \%$ answered - recommendations of friends, and recommendations of the seller (for example, in a bookstore, at a book exhibition) $-11.8 \%, 12.4 \%$ - reviews on social networks, on sales sites; reviews and reviews in the press and online media $-11.1 \%$, reviews on book sites $9.9 \%$, mentions on TV and radio $-4.7 \%$ (percentages are given for those who read books) [5].

If we consider in more detail the answers of the study all-Ukrainian sociological survey "Reading in the context of media consumption and life design" (2020), we can highlight the following book selection factors (\% of those who buy printed books): friends' recommendations (46\%), reviews on book sites (15\%), reviews on social networks, on sales sites $(15 \%)$, seller's recommendations (11\%), reviews and reviews in the press and online media (11\%), blogger recommendations, podcasts $(6 \%)$, mentions on TV and radio (5\%) [4].

Even though the questions in this study were posed somewhat differently, the general trend persisted.

Given the results of research on sources of information for readers and buyers of books, PR managers of publishing houses should pay attention to these online platforms, using them as channels of communication with readers and books buyers.

Conclusions. The formation of the corporate reputation, image and brand of the publishing house is influenced by media and non-media factors. Under the influence of communication, the sum of impressions of the target audience from the publishing houses is formed.

When launching certain PR campaigns, it is important for publishers to analyze what sources of information are used by the target audience of their books. According to the survey results, it can be concluded that the most active ways to promote books are Internet channels (sites and social networks), as well as recommendations from friends and acquaintances, who, in turn, also often share their opinions on the Internet and on social networks. Although the standard methods of promotion in the past through advertising, media, radio and television work, they are the least active. Media mentions and advertisements are important, but unfortunately, there are not have enough programs in books and reading in mass media. Book exhibitions and book cultural events are particularly popular among the respondents. From this we can conclude that it is important for publishers to actively promote books on social networks, to promote the publisher's brand in the media, since the brand or the well-known name of the publisher affects the audience.

Thanks to the media and other communication channels, the attitude of readers and other groups of the target public to a certain publishing house is formed, and the culture of reading in society in general increases. This is influenced by many factors and, above all, the media environment, both broad and narrow, in which publishers must intensify their communication activities if they want to develop their publishing business and the productive existence of their publishing houses.

\section{REFERENCES}

1. Bessarab A.O. Modern social and communicative technologies of reading culture formation of Ukraine book in the information society: abstract of thesis for a Doctor's of Social Communication degree by speciality 27.00.01 - theory and history of social communications. Classical Private University, Zaporizhia, 2017. $43 \mathrm{p}$.

2. Klyuchkovska H. Book promotion as an interaction of book business and mass media (principles of formation of the Ukrainian model): abstract of thesis for Cand. philologist. Sciences. Lviv, 2000. 20 p.

3. Krainikova T., Krainikov E., Yezhyzhanska T. Media behavior of youth in the COVID-19 pandemic in Ukraine. Innovative

Marketing. Volume 17, 2021, Issue \#1, pp. 94-108. http://dx.doi.org/10.21511/im.17(1).2021.08

4. Report on the results of the all-Ukrainian sociological survey "Reading in the context of media consumption and life construction". Kyiv, 2020. 181 p. https://book-institute.org.ua/uk/activity/doslidzhennya/doslidzhennya-2020

5. Ukrainian Reading and Publishing Data 2018 http://data.chytomo.com/en/pro-proekt/

6. Yezhyzhanska T., Krainikova T., Masimova L. Book PR: do readers influence on the communication of publishing company? Innovative Marketing. Volume 15 2019, Issue \#4, pp. 66-77. http://dx.doi.org/10.21511/im.15(4).2019.06 